\title{
Preparación de las niñas mayas para mejorar su calidad de vida
}

\author{
Jennifer Catino \\ Population Council \\ Alejandra Colom \\ Population Council \\ Marta Julia Ruiz
}

Follow this and additional works at: https://knowledgecommons.popcouncil.org/departments_sbsr-pgy

Part of the Demography, Population, and Ecology Commons, Family, Life Course, and Society

Commons, Gender and Sexuality Commons, and the International Public Health Commons

How does access to this work benefit you? Let us know!

\section{Recommended Citation}

Catino, Jennifer, Alejandra Colom, and Marta Julia Ruiz. 2011. "Preparación de las niñas mayas para mejorar su calidad de vida," Promoción de transiciones a la vida adulta sanas, seguras y productivas Resumen no. 5. New York: Population Council. 


\section{Preparación de las niñas mayas para mejorar su calidad de vida}

\section{Elaborado por Jennifer Catino, Alejandra Colom y Marta Julia Ruiz}

L a población de Guatemala es más pobre que la de la mayoría de los demás países de América Latina. Además, en Guatemala, el nivel educativo de la población es inferior, el crecimiento es más acelerado y existe una mayor diversidad étnica (Dries-Daffner et al. 2007). Las tasas de fertilidad (3,6 niños por mujer) y mortalidad infantil (30 muertes cada 1.000 nacimientos de bebés vivos) son unas de las más altas en la región (Figueroa et al. 2006; INE 2009). Casi la mitad de la población de Guatemala es aborigen, y más de 20 grupos étnicos mayas viven en áreas rurales aisladas, con acceso limitado a servicios básicos como agua, higiene, caminos, escuelas y cuidado de la salud. El 75\% de los habitantes mayas son pobres (INE 2008a). Aunque, en los últimos años, Guatemala ha progresado en el alcance de los Objetivos de Desarrollo del Milenio (MDG, por sus siglas en inglés), la disparidad persiste en términos de acceso a servicios y bienestar general en las poblaciones rurales y urbanas. Por ejemplo, a pesar de que la tasa nacional de fertilidad disminuyó de 5,6 a 3,6 niños por mujer entre 1987 y 2008, dicha tasa en mujeres aborígenes es 1,4 superior a la que se registra en mujeres no aborígenes (4,5 contra $3,1)$. La educación continúa ejerciendo influencia sobre las tasas de fertilidad. Las mujeres que no reciben educación tienen 5,2 niños, mientras que las mujeres que reciben educación secundaria o superior tienen 2,3 (INE 2009). Las niñas mayas son el grupo menos favorecido del país, su nivel de escolaridad es limitado, contraen matrimonio a una edad muy temprana, tienen hijos con frecuencia, están socialmente marginadas y son víctimas de la pobreza crónica (Hallman et al. 2006). Los investigadores del Population Council determinaron que estas niñas tienen acceso a solo unos pocos programas sociales. Una tarea imperiosa y esencial para alcanzar los Objetivos de Desarrollo del Milenio en Guatemala es crear recursos económicos, sociales y sanitarios para este grupo numeroso y desatendido.

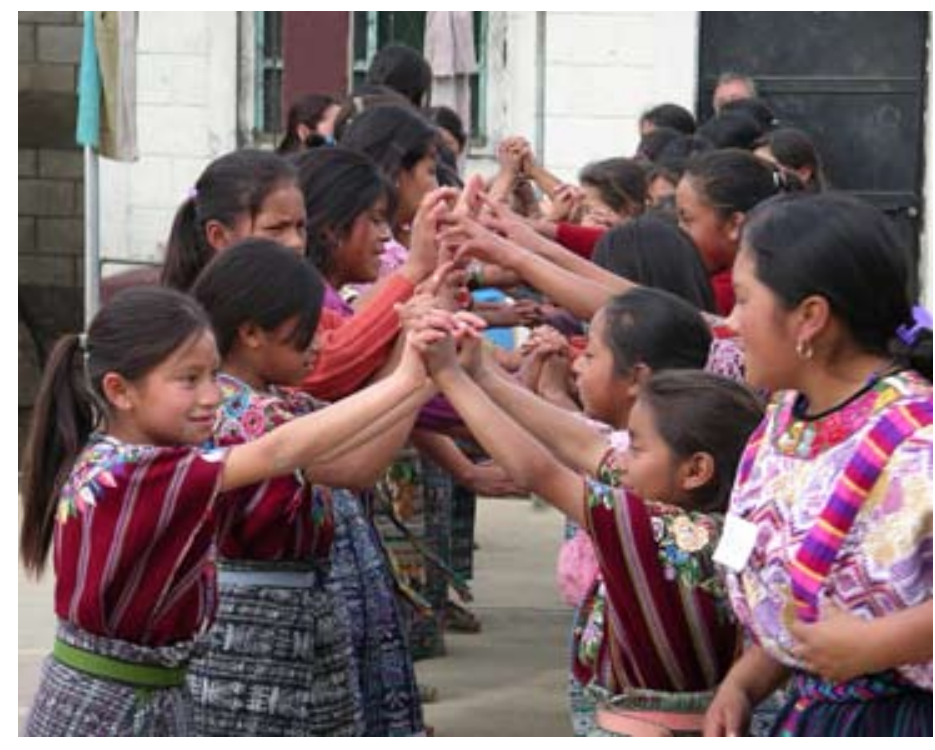

Las niñas mayores que participan en el programa se convierten en modelos positivos de roles para las niñas jóvenes.

Para ayudar a interrumpir el círculo de pobreza y permitirles a las niñas guatemaltecas alcanzar su máximo potencial, en 2004, el Population Council, en colaboración con diferentes socios locales e internacionales, lanzó un programa con el fin de incrementar las redes de apoyo social de las niñas mayas, conectarlas con modelos de roles y mentores, crear una base de habilidades esenciales para la vida cotidiana y el liderazgo, y brindar capacitación y experiencia profesional práctica. El programa ha evolucionado y su contenido y alcance se han ampliado. Además, se están desarrollando planes ambiciosos para que sea sostenible a nivel local y se institucionalice para que pueda llegar a más niñas. 


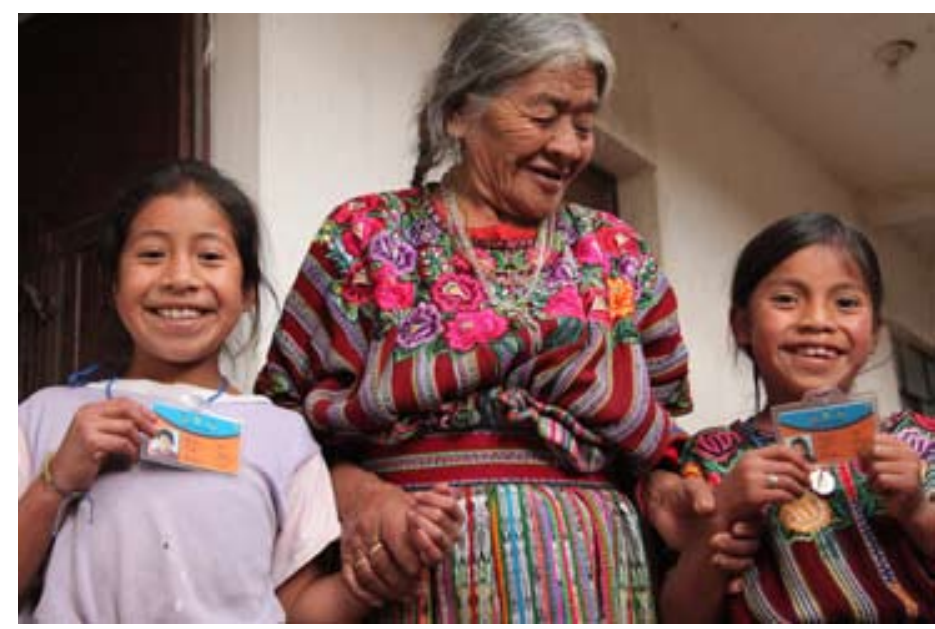

Proporcionar a las niñas mayas tarjetas de identificación emitidas por el programa les permite comenzar a desarrollar habilidades prácticas en la participación cívica.

\section{Abriendo Oportunidades: un programa nacional para niñas de zonas rurales crea recursos sociales, sanitarios y económicos} El programa conocido como Abriendo Oportunidades ("Opening Opportunities"), realiza importantes inversiones en niñas de 8 a 18 años de edad a fin de ayudarlas a afrontar exitosamente las transiciones de la adolescencia. Con la participación de líderes de la comunidad y mediante la capacitación de las niñas para que puedan administrar agrupaciones comunitarias, se crean espacios seguros en las comunidades rurales para que las niñas se reúnan, desarrollen habilidades y construyan redes sociales. Cuando las niñas aprenden habilidades prácticas y asumen roles de liderazgo, las familias y las comunidades se fortalecen. Los resultados de una reciente evaluación del programa determinaron que:

- 100 por ciento de las niñas líderes de Abriendo había completado el sexto grado, comparado con el 81,5 por ciento de las niñas que lo habían completado a nivel nacional. Además, había más niñas en la escuela a fines del ciclo del programa de 2009-10 (72 por ciento), comparado con el promedio nacional para niñas aborígenes (53 por ciento para las niñas de entre 13 y 15 años, y 29 por ciento para las niñas de entre 16 y 17 años) (USAID 2007);

- 97 por ciento de las niñas líderes de Abriendo no tuvieron hijos durante el ciclo del programa, comparado con el promedio de 78,2 por ciento de niñas de esa edad (15 a 19) a nivel nacional (Segeplan 2010);

- 94 por ciento de las niñas líderes de Abriendo manifestaron tener más autonomía y sentirse más cómodas cuando expresan sus opiniones, y el 84 por ciento dijo que su rol en el hogar había mejorado durante el ciclo del programa;

- 88 por ciento de las niñas líderes informó que tenía una cuenta bancaria y 44 por ciento ya había obtenido un empleo pago cuando el ciclo del programa finalizó.
Estos resultados indican que los programas que identifican e invierten en las niñas más vulnerables muestran signos de que no solo mejoran el bienestar de las niñas, sino que también cambian favorablemente las normas sociales y de género, y contribuyen a la reducción de la pobreza.

El programa actualmente se lleva a cabo en siete grupos étnicos mayas en Guatemala (Kiche', Kaqchikel, Tzutuhil, Mam, Q'eqchi', Pogomchi' y Chorti), participan más de 40 comunidades rurales en seis regiones geográficas de este país, y ha llegado a más de 3.500 niñas aborígenes de entre 8 y 18 años -y continúa expandiéndose. Las niñas del programa se dividen por edad en cohortes (8 a 12 y 13 a 18)-, y participan en un programa de actividades específicas del ciclo de vida. En cada ciclo anual de las agrupaciones de niñas, se identifican y capacitan nuevas mentoras/jóvenes líderes. Algunas niñas de más edad también se postulan para realizar prácticas profesionales pagas en instituciones locales del sector público y privado. A su vez, las jóvenes líderes reciben ayuda para formar y administrar agrupaciones en comunidades rurales. Las jóvenes líderes también reciben ayuda para establecer y mantener relaciones de colaboración con las autoridades locales.

Cada joven mentora conduce una agrupación de aproximadamente 40 niñas por ciclo. Los talleres que se llevan a cabo con las niñas y sus madres incluyen sesiones sobre autoestima, habilidades para la vida cotidiana, desarrollo de aspiraciones y planificación del futuro, la salud sexual y reproductiva, y la prevención del VIH/SIDA. El programa ha conectado a las agrupaciones rurales de niñas por medio del establecimiento de una Red de Recursos y Delegación de Poder para las Niñas Guatemaltecas Aborígenes (GIGREN, por sus siglas en inglés), que sirve como plataforma para que las niñas aborígenes defiendan sus necesidades y derechos tanto a nivel de la comunidad como a nivel nacional.

Después de la capacitación personal y profesional que recibí, comencé a organizar agrupaciones de niñas en mi comunidad para enseñarles las cosas que aprendí, compartir con ellas mi experiencia, motivarlas a soñar acerca de lo que desearían ser y trabajar mucho para alcanzar sus metas.

\section{_ Joven líder, Alta Verapaz}

\section{Con un vehículo para la acción y el cambio, las niñas ganan} confianza y poder de influencia

Como lo demuestra una reciente evaluación, el enfoque del programa es lograr cambios transformadores entre los participantes: el acceso de las niñas a modelos positivos de roles en la comunidad está aumentando, sus fuentes de apoyo social están creciendo, están ganando confianza y autoestima, y están aprendiendo nuevas habilidades. Además, las actitudes de la comunidad respecto del estatus social, la educación y la participación de las niñas en las actividades públicas han empezado a ser más positivas y solidarias.

Las niñas identifican la creación de espacios seguros cerca de sus hogares como un aspecto importante y muy apreciado del programa.

2 - Visite www.popcouncil.org/publications/serialsbriefs/TABriefs.asp para obtener todos los resúmenes de la serie Promoting healthy, safe, and productive transitions to adulthood (Promoción de transiciones a la vida adulta sanas, seguras y productivas). 
En estos lugares, las niñas pueden aprender, compartir y resolver problemas en compañía de otras niñas con entornos similares. Las participantes gozan de mayor autonomía y movilidad en la comunidad: pueden visitar los hogares de amigos y realizar excursiones educativas a otras comunidades. Desarrollan habilidades profesionales y de liderazgo, y planes más ambiciosos para su educación y sus vidas, lo que genera más respeto por parte de sus propias familias y comunidades.

Antes, ellos [nuestros padres] le permitían a mi hermano estudiar, porque era varón, digamos, pero no a mí. Pero ahora, he demostrado -creo que les he demostrado a mis padres- que puedo hacerlo. Porque antes... mi padre me decía que cuando terminara sexto [grado], "no vas a estudiar", y así era. Pero cuando este proyecto comenzó, me dieron la oportunidad de estudiar y ahora tengo mis metas y quiero graduarme. Quiero seguir estudiando.

-Joven líder, Sololá

La participación en el programa también ayuda a las niñas a superar dudas acerca de sus propias habilidades y cambiar las nociones tradicionales de género en sus comunidades. Cuando los padres y los líderes comunitarios ven que las niñas asumen nuevos roles y comienzan a conocer sus capacidades y su potencial, sus ideas sobre las niñas y sus oportunidades comienzan a cambiar.

Al crear estos tipos de oportunidades para las niñas en nuestras comunidades las ayudamos a mejorar su calidad de vida. Descubren y desarrollan habilidades y talentos que las ayudan a crear mejores oportunidades (educativas, profesionales, sanitarias y sociales) para ellas mismas. Esto es especialmente importante para las niñas, ya que ellas deben afrontar las mayores barreras. Nos encantaría ver a todos nuestros niños tener oportunidades como las que ofrece Abriendo Oportunidades.

\section{-Madre, Chimaltenango}

Las niñas también obtienen conocimientos y habilidades para la vida cotidiana. Desarrollan nuevas percepciones acerca del significado y las consecuencias de la violencia interpersonal, doméstica y social. Muchas desarrollan una mirada más orientada hacia el futuro y pueden articular objetivos más ambiciosos para ellas mismas, como postergar el matrimonio, volver a la escuela e intentar iniciar un pequeño negocio. Al recibir un estipendio y adquirir capacidades financieras básicas, las niñas pueden aprender a administrar mejor el dinero, pensar en ahorrar y prepararse para desarrollar un medio de vida productivo.

Mis objetivos son terminar la escuela primaria, graduarme y ser maestra, viajar y ganar mi propio dinero.

\section{—Niña participante, Totonicopán}

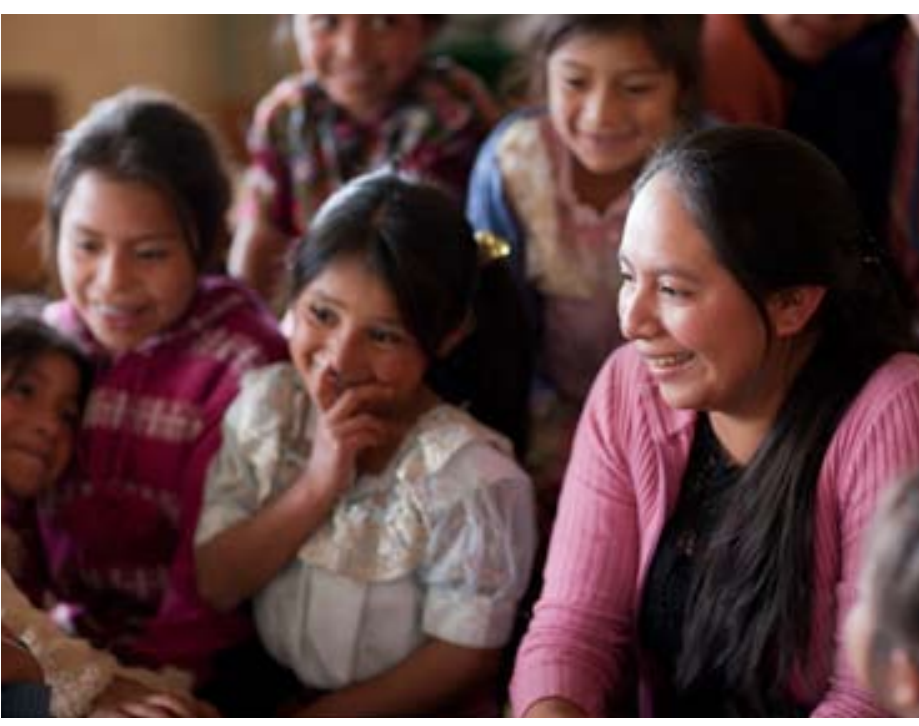

Las mentoras del programa les enseñan a las niñas habilidades de liderazgo y de la vida cotidiana.

En los años que transcurrieron desde que comenzó el programa, muy pocas jóvenes líderes se casaron y tuvieron hijos. Para quienes lo han hecho, sin embargo, la habilidad de permanecer conectadas con el programa y avanzar hacia planes de vida más amplios no se vieron afectadas. La mayoría de las jóvenes líderes del programa vuelven a la escuela y amplían sus objetivos educativos, lo que las ayuda a encontrar opciones de empleos más seguros y productivos. A medida que el programa se amplía, abarca un enfoque mayor en la construcción de las habilidades financieras de las niñas y las ayuda a desarrollar estrategias para ahorrar y obtener acceso a las cadenas de valor. Estos esfuerzos tienen la intención de ayudar a las niñas a obtener más conocimientos sobre finanzas y poner a su disposición mejores oportunidades de generar ingresos dignos.

Los debates con niñas y padres sugieren que las nuevas conexiones sociales y habilidades de las niñas tendrán beneficios a largo plazo y aumentarán sus posibilidades de conseguir un empleo y mejorar su estatus en la comunidad.

Gracias a Abriendo Oportunidades, las niñas y sus familias pueden apreciar las importantes relaciones que existen entre la salud, la educación y el trabajo. Las niñas solían abandonar la escuela porque no creían que la educación les ayudara a encontrar un empleo y disfrutar de una mejor calidad de vida.

Ahora podemos ver la importancia de la educación de las niñas. -Padre, Totonicopán

Las actitudes de la comunidad hacia los roles de las jóvenes líderes han cambiado con el tiempo. Al desarrollar habilidades que antes no existían en la comunidad, como el uso de computadoras, oratoria, liderazgo y experiencias de organización de la comunidad, las familias y las comunidades comienzan a apreciar y valorar más a las niñas. 
Cuando ellos (los líderes de las comunidades) necesitan algo, me llaman y me dicen: "podría hacernos el favor de ayudar con los jóvenes, llevar a cabo una actividad con ellos". Todo ha cambiado para mí desde que participo en el programa.

\section{-Joven líder, Chimaltenango}

La mayoría de las niñas que han participado en Abriendo Oportunidades permanecen conectadas entre sí y con el programa a través de la red nacional rural de niñas, reciben beneficios continuamente y contribuyen a la sostenibilidad y el crecimiento del programa. Las graduadas han sido contratadas como supervisoras de la ampliación del programa. Muchas han continuado su educación y han conseguido buenos empleos en el sector público y privado. Además, la mayoría de las jóvenes mujeres permanecen en sus comunidades, o regresan a ellas, y asumen roles de líderes, defensoras y ejemplos y catalizadores del cambio social. Otras han tenido la oportunidad de representarse a sí mismas y a otras niñas como ellas en políticas nacionales e internacionales, dando voz a quienes no la tenían.

El énfasis del programa actualmente está en la prevención de la violencia contra niñas y jóvenes mujeres. A pesar de la creciente prevalencia de la violencia social y de género en Guatemala, es poco lo que se hace en el ámbito de la prevención en general, y menos aún con un enfoque en las niñas aborígenes de zonas rurales. En respuesta a ello, Abriendo está trabajando con el sector público y socios locales de las ONG para capacitar a las jóvenes líderes en el abordaje de la violencia a nivel de la comunidad, y ayudar a niñas y jóvenes mujeres a mantenerse a salvo y saber cómo actuar ante la necesidad. Algunas actividades específicas son la capacitación y la ubicación de las jóvenes líderes como practicantes en empresas proveedoras de servicios que abordan la violencia de género en las comunidades rurales; realizar una "búsqueda de seguridad" con las niñas a fin de comprender dónde, cuándo y con quién se sienten seguras e inseguras; y diseñar conjuntamente estrategias para mitigar los riesgos. Las agrupaciones de niñas se usan como base para educar y promover el derecho a la seguridad, y brindar los recursos y la ayuda que las niñas y las jóvenes mujeres necesitan para terminar con la violencia en sus hogares y comunidades.

\section{Referencias y publicaciones relacionadas}

Colom, Alejandra, Marta Julia Ruiz, Jennifer Catino, Kelly Hallman, Sara Peracca, and Kristen M. Shellenberg. 2005. "Voices of vulnerable and underserved adolescents in Guatemala." Guatemala: Population Council.
Dries-Daffner, Ingrid, Kelly Hallman, Jennifer Catino, and Karla Berdichevsky. 2007. "Guatemala," en Jeffrey Jensen Arnett (ed.), International Encyclopedia of Adolescence. New York: Routledge.

Figueroa, Werner, Felipe Lopez, Lisa Remez, Elena Prada, and Joanna Drescher. 2006. "Early childbearing in Guatemala: A continuing challenge." In Brief, 2006 Series, No. 5. New York: Guttmacher Institute.

Hallman, Kelly, Sara Peracca, Jennifer Catino, and Marta Julia Ruiz. 2006. "Multiple disadvantages of Mayan females: The effects of gender, ethnicity, poverty and residence on education in Guatemala." Policy Research Division Working Paper No. 211. New York: Population Council.

_ 2007. "Indigenous girls in Guatemala: Poverty and location," en Maureen Lewis y Marlaine Lockheed (eds.), Exclusion, Gender and Schooling: Case Studies from the Developing World. Washington, DC: Center for Global Development.

Instituto Nacional de Estadística (INE) [National Statistical Institute]. 1999. Encuesta Nacional de Salud Materno-Infantil, 1998-1999. Guatemala: INE.

_. 2008a. Encuesta de condiciones de vida, 2006. Guatemala: INE. 2008b. Mujeres y hombres en cifras, Guatemala: INE.

2009. Encuesta Nacional de Salud Materno-Infantil, 2008-09. Guatemala: INE.

Segeplan. 2010. Tercer informe de avances en el cumplimiento de los objetivos de desarrollo del milenio, 2009. Guatemala: Segeplan.

Smith, Maria Baños, Marta Julia Ruiz, Luisa María Mazariegos, Jennifer Catino, and Guille Herrera. 2004. "Entendiendo y respondiendo a la violencia doméstica en comunidades indígenas de Guatemala". Guatemala: Population Council.

USAID. 2007. "Equidad de la Educación en Guatemala." Serie de Investigaciones Educativas vol. 4. Guatemala: USAID.

\section{Donantes}

Fundación Bill \& Melinda Gates, Departamento de Desarrollo Internacional del Reino Unido (DFID), Nike Foundation, Partridge Foundation, Research Triangle Institute/Alianzas/USAID, Summit Foundation, Fondo de Población de las Naciones Unidas (UNFPA), Fondo Fiduciario de las Naciones Unidas (UNTF)/ Fondo de las Naciones Unidas para las Mujeres (UNIFEM), Fundación William and Flora Hewlett

\section{Instituciones socias}

Asociación Renacimiento, Cooperativa para el Desarrollo Rural del Occidente (CDRO), Defensoría de la Mujer Indígena (DEMI), EngenderHealth, Federación de Salud Infantil y Reproductiva de Guatemala (FESIRGUA), Centro de Información, Capacitación y Apoyo a la Mujer (CICAM) Kiej de los Bosques, Mercy Corps, Pies de Occidente, Proyecto para el Desarrollo Sostenible de las Comunidades Ak'aba'al (Prodesca), Asociación Ajpatnar Chorti.

\section{Population Council}

El Population Council cambia la manera en la que el mundo piensa acerca de los problemas de salud y desarrollo. Buscamos entender las causas y las consecuencias de la desigualdad de género y las disparidades en las oportunidades que surgen durante la adolescencia. Brindamos las evidencias para desarrollar mejores programas y políticas prácticas que garanticen una transición exitosa y productiva hacia la edad adulta en los países en vías de desarrollo. www.popcouncil.org

() 2011 The Population Council, Inc

4 - Visite www.popcouncil.org/publications/serialsbriefs/TABriefs.asp para obtener todos los resúmenes de la serie Promoting healthy, safe, and productive transitions to adulthood (Promoción de transiciones a la vida adulta sanas, seguras y productivas). 